\title{
SIMPLES AGLOMERADOS OU SISTEMAS PRODUTIVOS INOVADORES? limites e possibilidades para a indústria do vestuário na metrópole paulista
}

\author{
Maria das Graças Brito \\ ROBERTO BERNARDES
}

\begin{abstract}
Resumo: O objetivo deste estudo é compreender a influência do espaço local na formação de configurações produtivas inovadoras no Município de São Paulo. Para este exercício analisamos e comparamos os padrões técnicos de duas aglomerações produtivas relevantes da indústria do vestuário. A metodologia utilizada baseou-se nas informações proporcionadas pela Pesquisa da Atividade Econômica Paulista e entrevistas qualitativas com atores locais.

Palavras-chave: Sistemas produtivos inovadores. Inovação. Aprendizado e indústria do vestuário.

Abstract: The objective of this research is to understand the influence of the local space for the emergence and organization of innovative local productive systems in the City of São Paulo. For the purpose two productive agglomerations of the clothing industry were analyzed and compared. The empirical data came from the survey "Pesquisa da Atividade Econômica Paulista - Paep", as well as from interviews with producers and institutions.

Key words: Innovative Production System. Innovation. Learning. Clothing Industry.
\end{abstract}

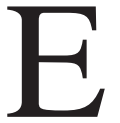
ste estudo aborda questões relativas aos espaços econômicos de aprendizagem e inovação do Município de São Paulo - MSP, pois entende-se que a Metrópole tenha preservado aglomerações produtivas muito diversificadas e representativas, ainda pouco exploradas na agenda de pesquisas sobre Sistemas Produtivos Inovadores Locais - SPILs. Com efeito, o papel exercido pela Região Metropolitana de São Paulo - RMSP na economia paulista e brasileira tem sido alvo de um crescente interesse, de onde surgiram estudos que se esforçaram em analisar a natureza e os impactos das transformações produtivas sob os mais diversos ângulos, tais como a interiorização do desenvolvimento (CANO, 1988; NEGRI, 1994), fragmentação produtiva e re-industrialização da metrópole (PACHECO, 1998), a desconcentração limitada (MATTEO; TÁPIA, 2002), emergência dos espa- ços e fluxos informacionais e a concentração dos segmentos intensivos em tecnologia (TINOCO, 2001), a metrópole de serviços produtivos e inovadores (ARAÚJO, 2001), dentre outros. Ainda assim, foram poucos os programas de pesquisa que aprofundaram a perspectiva da existência de vetores produtivos avançados ${ }^{1}$ ou embrionários nas regiões metropolitanas. Suzigan et al. (2004, p. 9-11), por exemplo, indicaram que não se presenciou processo de desconcentração das chamadas funções corporativas superiores, uma vez que os escritórios de administração central e os departamentos de engenharia e desenvolvimento de produtos permaneceram na antiga sede ou na unidade de produção principal, mesmo quando verificou-se queda do emprego e do faturamento. Isto ocorreu à revelia do processo de desconcentração industrial pelo qual passou a RMSP, caracterizado pelo movimento de relocalização de 
plantas em direção ao grande entorno, interior e outras unidades da federação como parte mais ampla de um processo de reestruturação industrial. Esse movimento explicaria a alta concentração de ocupações tecnológicas e das atividades de pesquisa e desenvolvimento - P\&D ou das chamadas "funções corporativas inteligentes" na RMSP. Já nos estudos direcionados ao espaço do MSP, propriamente dito, encontram-se as análises mais recentes sobre as estratégias de desenvolvimento da Área Central (COMIN et al., 2002; GARCIA; CRUZ-MOREIRA, 2004; BESSA, 2004) e o papel das redes produtivas na indústria do vestuário (KONTIC, 2002). Ainda assim, a capacidade socioprodutiva de articulação institucional e local dos atores na Metrópole Paulista ainda é um tema pouco explorado, assim como as especificidades e heterogeneidade das aglomerações produtivas (SCOTT, 1994).

Nesse sentido, o objetivo deste estudo é compreender a influência do MSP na inovação e organização de SPILs. ${ }^{2}$ Para identificar e comparar as características dos aglomerados produtivos no MSP, optou-se por pesquisar a indústria do vestuário - e, mais especificamente, duas aglomerações relevantes para o setor cujos padrões de competitividade e a trajetória evolutiva das competências mostraram-se distintos. Foram identificadas duas aglomerações historicamente consolidadas e relevantes para o setor. A primeira é a denominada Aglomeração da Área Central - AAC, pois a indústria do vestuário está fortemente concentrada no distrito de Bom Retiro. Seus esforços por aprendizado e inovação buscam o desenvolvimento de design, investimento na marca e lançamento de novos produtos da moda. Como essa área mantém interações mais sensíveis com o mercado e instituições locais, apresenta elementos potenciais para a constituição de uma trajetória em direção a um sistema de produção inovador. A segunda é a denominada Aglomeração da Área Leste - AAL, pois seu núcleo produtivo está localizado nas imediações dos distritos Brás/Pari/Belém. A metodologia adotada utilizou os dados disponibilizados pela Pesquisa da Atividade Econômica Paulista - Paep, da Fundação Seade, assim como informações obtidas a partir de entrevistas qualitativas com atores locais.

Este artigo está organizado em seis partes, além da introdução. Na primeira parte, é descrita a metodologia, que adotou como principal fonte de informação a Paep 2001, além de um trabalho de campo que coletou entrevistas qualitativas com atores locais dos dois aglomerados estudados. Na segunda parte, serão analisados os indicadores referentes à identificação dos aglomerados da indús- tria do vestuário (aplicação de técnicas de georreferenciamento e quociente locacional para as grandes áreas do MSP). Na terceira parte, são tratados os elementos históricos que influenciaram as trajetórias de constituição e aprendizado desses aglomerados. A análise das performances de eficiência dos dois aglomerados é operada na quarta parte. Já no quinto tópico discute-se o processo de inovação para a indústria do vestuário, que é seguido pela efetiva comparação entre as estratégias tecnológicas e a apropriação das chamadas funções inteligentes. Na sexta parte, serão comparados aspectos relativos aos mecanismos de interação, tanto os voltados para a organização produtiva do aglomerado, quanto os que fazem interação com o ambiente. Em seguida, são apontadas as principais conclusões.

\section{INDICADORES DE AGLOMERAÇÕES E BASE DE INFORMAÇÕES}

A principal fonte de informação utilizada neste estudo é a Pesquisa da Atividade Econômica Paulista - Paep, da Fundação Sistema Estadual de Análise de Dados - Seade, do ano de $2001 .^{3}$ Os dados estatísticos foram complementados com informações obtidas das pesquisas qualitativas com atores locais. Tal pesquisa foi baseada em entrevistas com cinco representantes de empresas produtoras e instituições locais e obviamente não teve o intuito de contemplar a representatividade estatística (já obtida com os dados da Paep). Sua contribuição foi no sentido de identificar e qualificar as informações que não são passíveis de captação através da Paep - como as especificidades das interações locais, os eventos históricos e as instituições de apoio à atividade de cada aglomerado estudado, dentre outros aspectos.

A representatividade estatística foi obtida junto à Paep. Pesquisa de caráter amostral radiografou a atividade econômica e tecnológica priorizando os condicionantes setoriais e regionais das empresas no Estado de São Paulo - ESP nos anos de 1996 e 2001. ${ }^{4}$ A amostra da Paep é composta por dois estratos: o certo, formado por um censo das empresas com mais de 30 pessoas ocupadas em 2001; e um estrato aleatório, que arrola as empresas abaixo deste limite. Foram pesquisadas, com a aplicação de questionário, apenas as empresas juridicamente estabelecidas que operaram em 2001 no Estado de São Paulo. As empresas com sede fora do Estado foram mantidas na pesquisa somente quando o conjunto das unidades produtivas paulistas somava mais de 30 pessoas ocupadas. $\mathrm{Na}$ indústria do 
vestuário, que é o setor de interesse deste estudo, somente as empresas que mantinham no mínimo cinco pessoas ocupadas em 31 de dezembro de 2001 foram consideradas como pertencentes "ao âmbito".

Esse estudo cobriu 46.225 empresas que foram divididas em grupos (denominados "domínios"), para os quais calculou-se erro relativo e coeficiente de confiança compatíveis com esse tipo de pesquisa. Mas dadas as características de cada setor e região, é possível calcular estimativas alternativas ao desenho da pesquisa, desde que sejam respeitadas as regras de sigilo das informações e controle do erro amostral. ${ }^{5}$ A indústria do vestuário foi escolhida por ter sido apontada como o maior empregador industrial do MSP, pois mantinha uma concentração superior a $50 \%$ do setor no Estado e caracterizava-se ainda como uma das atividades mais relevantes para a dinâmica socioeconômica do MSP.

Assim, o passo inicial foi identificar e selecionar os principais aglomerados produtivos da indústria do vestuário do MSP. Contudo, verificou-se que, devido ao adensamento econômico da metrópole, as vocações produtivas ficavam camufladas em meio à diversidade da estrutura produtiva regional, dando a impressão de que a dinâmica econômica do setor seria resultado de um grande número de empresas dispersas. Para contornar tal problema, foi utilizado um recorte geográfico mais desagregado, que divide os limites do MSP em cinco grandes áreas - Norte, Sul, Leste, Oeste e Centro (regionalização utilizada pelos Correios $^{6}$ ) - e, a partir daí, foi feito o registro de localização das unidades industriais. Tal escolha metodológica teve como objetivo identificar as concentrações produtivas mais relevantes, tendo em vista o respeito aos limites amostrais. Por isso, optou-se por trabalhar com grandes áreas como proxy das aglomerações, em detrimento de outras regionalizações espaciais mais detalhadas, como as de distritos ou subprefeituras.

Os dados das unidades do cadastro Cempre foram localizados geograficamente no Mapa 1, elaborado a partir de georreferenciamento, onde foi possível visualizar os efeitos de aglomeração (clustering). Para denotar a importância local dos aglomerados e dar prosseguimento aos exercícios analíticos de caracterização, foi aplicado o Quociente Locacional (QL), indicador já consagrado na bibliografia como medida de concentração econômica (HADDAD, 1989, SUZIGAN et al., 2002), ${ }^{7}$ para o total de pessoas ocupadas (PO) e de valor adicionado (VA), da Paep, para as unidades produtivas do setor do vestuário evitando, dessa forma, supervalorizar a identificação ba-

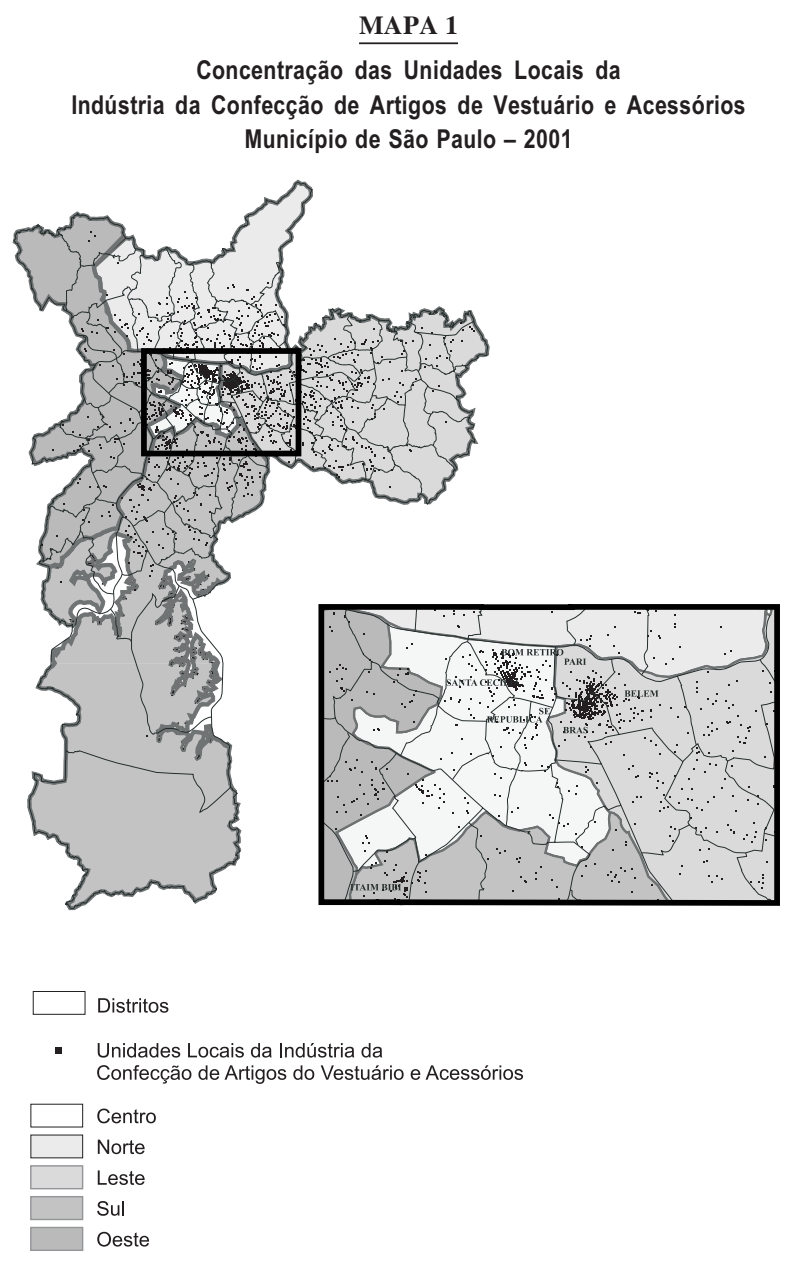

Fonte: Fundação Seade. Cadastro de Unidades Locais 2001. Nota: Divisão da cidade segundo a Empresa de Correios e Telégrafos.

seada no produto ou no emprego. Após a identificação, seguiu-se um esforço para caracterizar e comparar as estratégias tecnológicas do processo de aprendizado e inovação dos aglomerados identificados. Para tanto, foi preciso dimensionar a influência dos eventos históricos de constituição e performance da produtividade, assim como as possibilidades de acumulação de conhecimento, os mecanismos de aprendizado e a intensidade da interação local.

\section{IDENTIFICANDO AGLOMERAÇÕES DA INDÚSTRIA DO VESTUÁRIO NO MUNICÍPIO DE SÃO PAULO}

Para conferir a existência de aglomerações industriais no MSP, utilizou-se o recurso do georreferenciamento para as informações de unidades locais - ULs. Através da 
visualização cartográfica proporcionada pelo Mapa 1 é possível identificar com bastante nitidez que a indústria do vestuário está disseminada por quase toda a extensão do MSP. Contudo, as evidências de manchas de aglomeração, como podem ser observadas, são mais apropriadas às condições oferecidas pela Área Central e pela Área Leste. Por meio da visualização cartográfica das informações sobre ULs da Paep 2001, observa-se que essas áreas apresentam manchas de aglomeração de empresas bem delineadas. Nota-se que, mesmo com aplicação do zoom (imagem destacada à direita do Mapa 1), as aglomerações continuam densas. Porém, é importante deixar claro que as evidências das duas aglomerações não respondem a questões relativas ao peso econômico dessas aglomerações na indústria do vestuário paulista.

Para denotar a importância do aglomerado para as localidades, foi aplicado o quociente locacional (QL) como índice de concentração econômica destas atividades (Tabela 1). Por meio desse indicador, foi possível dizer que as aglomerações mapeadas a partir das ferramentas de georreferenciamento demonstram a importância relativa da Área Central e da Área Leste, já que em ambas o QL é maior que dois para pessoas ocupadas - PO e maior que três para o valor adicionado - VA. Isso demonstra que, além de haver concentração elevada na indústria do vestuário nas referidas áreas, há também consistência e relevância econômica desse setor nessas localidades (Tabela 1) - e isso ocorre tanto quando se considera a variável de PO quanto a de VA. Ressalta-se que a Área Oeste também demonstrou alta concentração na indústria do vestuário, com QL superior a 1; porém, como pode ser observado no Mapa 1 , nessa área não foram verificados efeitos de aglomeração de maior densidade, tal como os presenciados na Área Central e na Área Leste - por isso, ela foi descartada da análise.

TABELA 1

Quociente Locacional por Valor Adicionado e Pessoal Ocupado do Vestuário, segundo Áreas Selecionadas

Município de São Paulo - 2001

\begin{tabular}{lcc}
\hline Áreas Selecionadas & QL Valor Adicionado & QL Pessoal Ocupado \\
\hline Município de São Paulo & 3,47300 & 2,1679 \\
Área Central & 3,55932 & 3,43059 \\
Área Leste & 5,17883 & 2,86763 \\
Área Oeste & 1,17888 & 1,17168 \\
Área Sul & 0,95173 & 0,86678 \\
Área Norte & $(1)$ & $(1)$ \\
\hline
\end{tabular}

Fonte: Fundação Seade. Pesquisa da Atividade Econômica Paulista - Paep 2001. Elaboração dos autores.

(1) Dado não disponível.
A secção dos limites do MSP em grandes áreas produtivas proporcionou maior visibilidade aos aglomerados da indústria do vestuário, possibilitando uma percepção mais adequada sobre a importância que as atividades produtivas e econômicas dessas localidades ocupam no MSP. Destaca-se ainda que os resultados expressivos do QL também indicam que é possível avaliar os aglomerados da indústria do vestuário das Áreas Leste e Central do MSP enquanto "um conjunto específico de atividades econômicas que apresentam vínculos mesmo que incipientes" (CASSIOLATO; LASTRES, 2003). Portanto, eles têm potencial para se enquadrarem como SPILs organizados, mas, para tanto, a identificação dos aglomerados não é suficiente - fato que remete à avaliação das características estruturais e de dinamismo do comportamento inovador.

\section{TRAJETÓRIAS CONSTITUTIVAS E ELEMENTOS ESTRUTURAIS DO APRENDIZADO LOCAL}

O aglomerado da indústria do vestuário da Área Central - AAC do MSP é fortemente concentrado no distrito do Bom Retiro, sendo que seu processo de constituição está relacionado aos chamados eventos fortuitos (SCOTT, 1998) e esteve associado aos movimentos de atração dos fluxos migratórios da colônia judaica para essa localidade até o fim dos anos 70. A partir dos anos 80, presencia-se nessa localidade a entrada de novos imigrantes que se inserem na produção do vestuário, especialmente os coreanos, os quais rapidamente passaram a dominar as atividades produtivas. É nesse período que se inicia um ciclo de revitalização das estratégias competitivas do vestuário local. Nas entrevistas realizadas, os empresários locais destacaram o ímpeto competitivo da colônia coreana, classificando-o como o dínamo vital para a o ressurgimento da indústria do vestuário naquela região. A participação econômica produtiva desse aglomerado, inicialmente direcionada para a produção artesanal de baixa escala, atualmente está voltada para o segmento do chamado prêtà-porter, produto que combina a estratégia de desenvolvimento incremental de design com a produção em escala. ${ }^{8}$

O núcleo da aglomeração produtiva da Área Leste AAL está localizado nas imediações do Brás/Pari/Belém. Os imigrantes italianos formaram a primeira colônia a instalar-se nessa área onde já se encontravam algumas fábricas têxteis. Os fatores que explicam o surgimento e a expansão desse aglomerado ali, estão historicamente associados à facilidade de obtenção de insumos, às poucas barreiras de entrada no mercado, à baixa capacidade 
de investimentos e de concentração capital necessária para a abertura de uma nova unidade de produção do vestuário. Além disso, como destaca Kontic (2002), o Brás também recebeu os fluxos migratórios do nordeste brasileiro, embora, a partir da década de 80, essa área também tenha absorvido coreanos, assim como imigrantes andinos. Os migrantes nordestinos, como aponta Kontic (2002)

passaram de representantes comerciais a produtores de produtos mais baratos em grande escala. Nesse sentido, foram capazes de beneficiar-se do parque industrial existente e do conhecimento acumulado do perfil da demanda local, além de utilizar uma estratégia de crédito bastante eficiente, baseada na confiança nos compradores, que outros grupos paulistas $e$ catarinenses não ousaram estabelecer. Com o crescimento do comércio atacadista no centro da cidade, foram deslocando suas oficinas para a Zona Leste e Guarulhos.

Tradicionalmente, os produtos fabricados na Área Leste sempre tiveram características simples, destinadas ao público de mais baixa renda, sendo suas vantagens competitivas decorrentes do fator preço. Conseqüentemente, condicionado por fatores sociais e econômicos, esse aglomerado demonstrou ter uma vocação produtiva para a participação econômica em artigos de "modinha" que, embora tenham algum tipo de preocupação com o design, normalmente são resultados de réplicas, não requerendo maiores esforços de inovação ou de diferenciação de produtos.

Em grandes linhas, percebe-se que a diversidade do "capital sociocultural" é um elemento comum aos dois aglomerados, mas observa-se que a formação de cada um foi influenciada por eventos históricos e econômicos estruturalmente distintos. No AAC observa-se, inicialmente, o processo de revitalização gerado pelo ímpeto inovador da colônia coreana. Já no AAL, a presença das grandes indústrias têxteis e a de um grande contingente de trabalhadores semiqualificados parece ter viabilizado a indústria do vestuário nessa localidade. Mas é interessante notar que, durante a trajetória de desenvolvimento dos dois aglomerados, as características mais estruturais da produção aparentemente não foram alteradas, o que ocorreu, na verdade, foi um reforço de readaptação das opções já delineadas a partir de sua própria origem.

As pequenas empresas de vestuário, que são a base de composição dos dois aglomerados, são, em boa parte, formadas por trabalhadores originários das chamadas "oficinas" que fazem a facção do setor - ou seja, pequenas empresas que se encontram nos extremos da cadeia de produção e realizam, normalmente, uma única fase do pro- cesso produtivo (como a costura, bordado, arremate, etc.) que, numa trajetória quase natural, tentam progredir no sentido de alcançar outros mercados. Mas não são raros os casos em que os novos empreendedores dão início aos negócios de forma precária e pouco profissional, resultando em um comportamento errático, com poucas perspectivas de desenvolvimento e maturação da atividade empresarial. ${ }^{10}$ Tal precariedade na formação profissional e negocial dos executivos e trabalhadores de muitas dessas empresas tem implicações inexoravelmente negativas para o aprendizado tecnológico dos aglomerados. Como observado na indústria do vestuário, empresas que disponham da oferta de profissionais qualificados tendem a se beneficiar do conhecimento derivado do aprendizado interativo, tácito e cumulativo, que são adquiridos nas relações e práticas rotineiras e de intercâmbio de informações interfirmas (STORPER; SALAIS, 1997). Assim, a apropriação dos ativos decorrentes da dimensão intertemporal num ambiente metropolitano, viveiro de novos conhecimentos, mercados e negócios diferenciados, torna-se fundamental para a competitividade dos aglomerados - mas, como será mostrado, esse fenômeno é relativamente incomum.

Observa-se, na Tabela 2, que o AAC possui condições mais apropriadas para absorção dos ativos relacionados à acumulação de conhecimento e experiência, pois até 1980 cerca de $78 \%$ das unidades já se encontravam instaladas nesse aglomerado. Cabe lembrar que o período 1980-90 combina a entrada mais acentuada dos coreanos nas atividades da indústria do vestuário com a abertura de mercado - e esses fenômenos tiveram influência nos dois aglomerados.

TABELA 2

Unidades Produtivas da Indústria do Vestuário na Área Central e Leste, segundo Período de Instalação Município de São Paulo - 1980-2001

\begin{tabular}{|c|c|c|c|c|}
\hline \multirow{2}{*}{$\begin{array}{l}\text { Período de } \\
\text { Instalação }\end{array}$} & \multicolumn{2}{|r|}{ Central } & \multicolumn{2}{|r|}{ Leste } \\
\hline & $\%$ & $\%$ Acumulada & $\%$ & $\%$ Acumulada \\
\hline Até 1980 & 26,9 & 26,9 & 17,8 & 17,8 \\
\hline Até 1990 & 51,5 & 78,5 & 28,9 & 46,7 \\
\hline Até 1995 & 7,9 & 86,4 & 33,2 & 79,9 \\
\hline Até 2001 & 13,6 & 100,0 & 20,1 & 100,0 \\
\hline
\end{tabular}

Fonte: Fundação Seade. Pesquisa da Atividade Econômica Paulista - Paep 2001. Elaboração dos autores.

Quanto a esse assunto, a nossa percepção é a de que o segmento de vestuário do AAC tenha se demonstrado uma "janela de oportunidade" para os coreanos, antecipando 
a entrada dos novos empreendedores, propiciando a adaptação mais rápida frente aos novos padrões competitivos, além de gerar unidades produtivas aparentemente mais consolidadas e com escalas técnicas mais eficientes. Destaque-se que, nas entrevistas, os produtores consideraram que, de modo paradoxal, a abertura ao mercado externo teve algum tipo de efeito positivo para o setor, mesmo diante do fechamento de várias empresas, pois possibilitou o acesso aos novos insumos - o que era uma antiga reivindicação dos produtores, principalmente, da colônia coreana. Já no caso do AAL, o período de instalação é bastante distinto, pois o início de funcionamento das unidades locais foi mais tardio. Até 1990, menos da metade das unidades encontravam-se instaladas, demonstrando que esse aglomerado implementou seu processo de reestruturação em um período mais recente, impulsionado pela abertura de mercado (Tabela 2).

\section{PERFORMANCE DA EFICIÊNCIA DOS AGLOMERADOS}

Naturalmente, a diferenciação nas características constitutivas de acumulação de competências, assim como a assimetria entre as estratégias tecnológicas e organizacionais no AAC e no AAL provocam impacto na performance competitiva. Exatamente por ser uma atividade intensiva em trabalho, o indicador de produtividade - medido pela razão entre VA sobre $\mathrm{PO}$ - pode representar uma proxy razoável da performance da eficiência dos aglomerados, já que, com a tendência crescente de valorização dos investimentos em ativos intangíveis nesse setor, a produtividade também tem assumido padrões cada vez mais dinâmicos.

Nesse sentido, observa-se que a produtividade do AAC sugere uma organização do conjunto produtivo mais eficiente quando comparado ao AAL, assim como às demais regiões do ESP, $20 \%$ e $60 \%$, respectivamente. Ressalve-se que, em relação ao total da indústria do Estado, o indicador de produtividade do aglomerado central é 14\% superior. Quanto ao AAL, ainda que a produtividade seja inferior ao AAC, apresenta desempenho quase duas vezes superior às demais regiões do ESP, mas abaixo da média do Estado (Tabela 3).

Tal desempenho também indica que, mesmo tendo sido identificadas outras aglomerações produtivas em regiões fora da metrópole - como as localizadas em Americana ${ }^{11} \mathrm{e}$ Amparo $^{12}$ - a competitividade dessas localidades mostramse menos dinâmicas frente às duas grandes aglomerações do MSP, formadas, basicamente, por pequenas e médias empresas.
TABELA 3

Índice de Produtividade dos Aglomerados do Vestuário da Área Central, Leste e Demais Regiões Estado de São Paulo - 2001

\begin{tabular}{lc}
\hline Áreas Selecionadas & Índice de Produtividade \\
\hline Estado de São Paulo & 100,0 \\
Área Central & 114,7 \\
Área Leste & 87,5 \\
Demais Áreas do ESP & 43,3 \\
\hline Fonte: Fundação Seade. Pesquisa da Atividade Econômica Paulista - Paep 2001. Elabo- \\
ração dos autores.
\end{tabular}

\section{NATUREZA E DINÂMICA DA INOVAÇÃO NAS ATIVIDADES DA INDÚSTRIA DO VESTUÁRIO}

A indústria do vestuário tem alterado suas características mais convencionais, como resultado da estabilidade do regime tecnológico e de sua complexidade produtiva relativamente baixa. Também tem sido crescente a adoção dos ativos da moda ${ }^{13}$ como estratégia de mercado pelos principais segmentos (modinha, prêt-àporter e alta costura) (KONTIC, 2001). A estratégia baseada na diferenciação/fragmentação ou em moda é estruturada sobre critérios de concepção do produto, qualidade e comercialização como fatores críticos de sucesso. As empresas que adotam essa estratégia competitiva procuram diferenciar ao máximo seus produtos, requerendo rapidez de resposta aos sinais do mercado, além de incentivar a criatividade e inovação de produto. Caracterizam-se, portanto, pela produção de itens não padronizados, de maior valor agregado e em quantidades limitadas - o que permite lucratividade elevada.

Sob a ótica das atividades tecnológicas da indústria do vestuário, as principais fontes de inovação e aprendizado são provenientes da difusão das tecnologias de informação, automação com dispositivos de corte a laser e ferramentas tecnológicas associadas ao design e engenharia de projeto. Com efeito, nesse segmento, os maiores avanços ocorreram no desenho e no corte, pela utilização de sistemas CAD (computer aided design) e CAM (computer aided manufacturing). Entretanto, grande parte das empresas desse segmento desenvolvem suas operações produtivas de forma não automatizada, não suprimindo as atividades artesanais e manuais no processo produtivo baseadas ainda na relação um operador/uma máquina (LUPATINI, 2004).

Ainda que o progresso técnico e os investimentos em ativos materiais (considerando máquinas e equipamentos 
e melhorias incrementais das matérias-primas) permaneçam relevantes, constata-se que os ativos imateriais (intangíveis) são cada vez mais essenciais para a sustentação das vantagens competitivas dessa indústria do vestuário. Os bens intangíveis estão relacionados às rotinas anteriores e posteriores à produção que estão mais próximas dos serviços produtivos, tais como o desenvolvimento de produto (onde se inclui a pesquisa indumentária e antropométrica), engenharia, marketing, canais de comercialização, marcas, manutenção e assistência aos fornecedores, capacidade de gestão e coordenação da cadeia, que são consideradas por diversos autores como "funções corporativas inteligentes" (STURGEON, 1997; FURTADO, 2000; LUPATINI, 2004; GARCIA; CRUZ-MOREIRA, 2004). Dadas as características do processo de inovação e aprendizado na indústria do vestuário, analisaremos a seguir as condições de apropriação e as estratégias tecnológicas dos AAC e AAL do MSP.

\section{COMPARANDO AS ESTRATÉGIAS DE INOVAÇÃO NOS AGLOMERADOS}

A Paep buscou compreender o impacto das transformações tecnológicas e produtivas por vários ângulos, nos quais estão incluídas as questões relativas à introdução de inovação tecnológica. ${ }^{14}$ As informações sobre inovação foram captadas entre julho de 2002 e junho de 2003, o que permitiu a análise de diversos segmentos da atividade econômica industrial paulista durante o período 1999-01. Assim, foi possível verificar, por meio da descrição dessas inovações, que a mensuração desse evento está muito vinculada à inovação do processo. Ou seja, essas empresas inovam basicamente através da absorção das novas tecnologias geradas por outros setores, incorporando tecnologias de informação e comunicação, novas ferramentas de engenharia de projeto e processo como CAD/CAM, técnicas de colorimetria, ploters, máquinas de costura eletrônica a laser, entre outras (Quadro 1).

Com efeito, essa análise buscou caracterizar as aquisições de bens tangíveis e intangíveis como proxy do esforço tecnológico que se mostraram mais aptos às características do setor. ${ }^{15}$ Pela análise do Gráfico 1 , verifica-se que a estratégia adotada pelo AAC concentra seus esforços tecnológicos nos bens intangíveis, ${ }^{16}$ valorizando a absorção de tecnologia e de novos conhecimentos derivada de marcas, e também em conseqüência de desenvolvimento de produto e design próprio. No caso dos investimentos em bens corpóreos - que representam grande parcela da inovação no setor - o esforço é equivalente tanto para máquinas e equipamentos (18\%) como para os outros bens tangíveis, ${ }^{17}$ que representam $20 \%$. Já no caso do AAL, o esforço tecnológico está voltado basicamente para a modernização dos bens corpóreos, especialmente máquinas e equipamentos que representam mais de $80 \%$ das aquisições, apresentando um padrão tecnológico dentro do esperado para o setor. Esse esforço expressivo para a aquisição de máquinas e equipamentos oferece indícios que sugerem que a estratégia tecnológica do AAL está mais direcionada para produção em escala ou para a facção, o que não necessariamente pode ser uma opção inviável se

QUADRO 1

Principais Inovações Tecnológicas de Produto e Processo Introduzidas nas Empresas do Vestuário Município de São Paulo - 1999/2001

\begin{tabular}{lc}
\hline Inovações de Produto & Inovações de Processo \\
\hline - Nova confecção em tecido mais leve com & • Máquina eletrônica de alta velocidade - high speed - \\
aplicação de tecnologia mais avançada & na produção \\
- Nova coleção de camisas de futebol com características de & • Sistema CAD e Ploter para automatização de risco e \\
hidrofilia, que favorece a eliminação do suor & corte (Máquina com corte laser) \\
- Nova linha de colchas com o beneficiamento & • Introdução de códigos de barras e informatização na modelagem de \\
do tecido. & projetos (CAD) \\
- Malhas especiais com novos fios de poliéster & • Estações Gráficas de Sistemas CAD-CAM \\
- Nova coleção com tecidos aperfeiçoados com novos insumos & • Comércio eletrônico de camisas sob medida. Com o conceito BTO \\
(a cada quatro meses é renovada a coleção de acordo com as & (construção sobre demanda ao varejo) EDI - Intercâmbio Eletrônico de \\
tendências da moda) & Dados \\
\hline
\end{tabular}

Fonte: Fundação Seade. Pesquisa da Atividade Econômica Paulista - Paep 2001. Elaboração dos autores. 
GRÁFICO 1

Composição do Esforço Tecnológico das Empresas da Indústria do Vestuário, por Tipo de Dispêndio

Estado de São Paulo e Áreas do Município de São Paulo - 2001

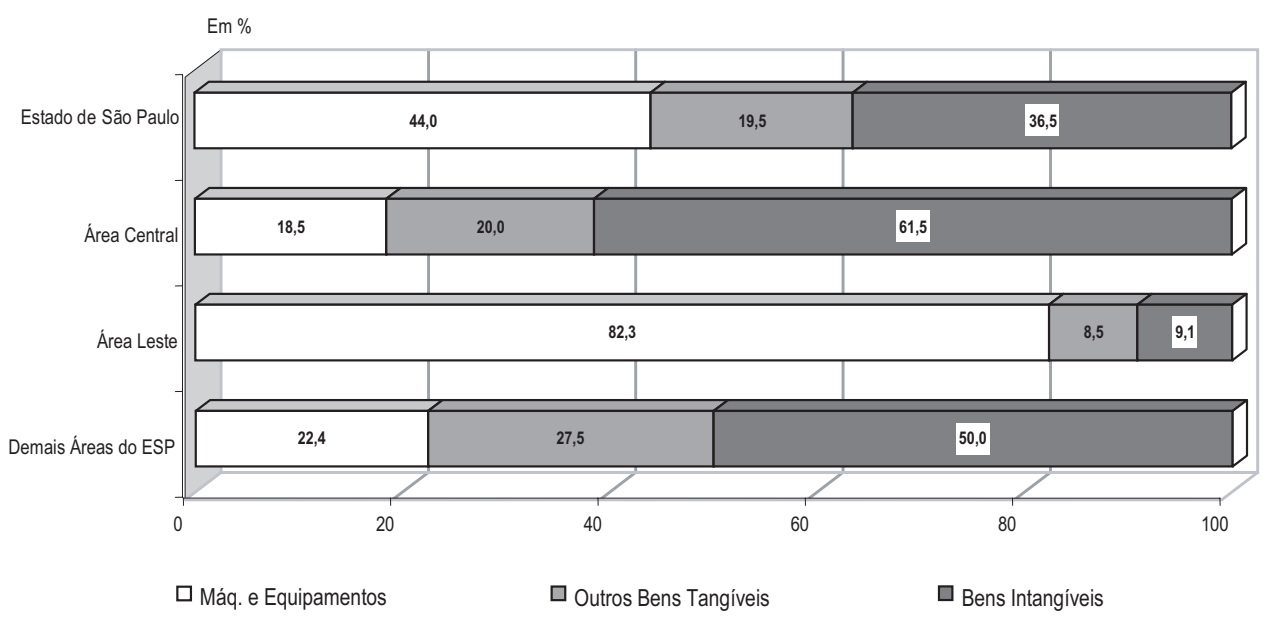

Fonte: Fundação Seade. Pesquisa da Atividade Econômica Paulista - Paep 2001. Elaboração dos autores.

a estratégia competitiva for baseada em produção padronizada ou prestadora de serviços de facção.

Ampliando a análise das estratégias tecnológicas para o Estado de São Paulo, nota-se que a repartição do investimento também é concentrada em máquinas e equipamentos - o que representa o maior esforço, com $44 \%$ do montante investido. Seguem-se os bens intangíveis, com 36,5\% (Gráfico 1). É provável que o esforço tecnológico dedicado aos bens tangíveis nos demais municípios dos ESP esteja sendo influenciado pelas empresas do vestuário da RMSP, onde estão instaladas algumas grandes companhias de moda.

\section{A CONCENTRAÇÃO DAS FUNÇÕES INTELIGENTES}

Estudo elaborado por Garcia e Cruz-Moreira (2004), mostra que a RMSP tem perdido participação na produção de artefatos de tecidos, mas ainda possui participação relevante na dinâmica da cadeia têxtil-vestuário, uma vez que parcela significativa da produção do vestuário ainda é manufaturada na região. Além disso, o elemento mais estratégico observado nesse estudo é a centralização das chamadas funções inteligentes ${ }^{18}$ das empresas pertencentes ao segmento do vestuário no MSP. Essas novas funções de inteligência estão ligadas aos ciclos de desenvolvimento e gerenciamento de novos projetos e design ${ }^{19}$ (produto). As tarefas associam-se à elaboração das coleções, inserção internacional, estratégia de marketing, ${ }^{20}$ reforço da marca (projeto) e no desenvolvimento dos fornecedores do produto. ${ }^{21}$

Observa-se, na Tabela 4, que o desenvolvimento e gerenciamento de um projeto é uma tarefa limitada a poucas empresas nos aglomerados. Mesmo assim, a absorção dessas tarefas ocorre em proporção superior no AAC. Chama a atenção que tais tarefas são, em sua maioria, contratadas - o que indica que profissionais especializados nas tendências (os consultores de moda), interagem com as empresas do aglomerado, bem ao estilo do prêt-à-porter, alinhando-se perfeitamente às estratégias do aglomerado Central - mas são muito pouco presenciadas no AAL. Na etapa de desenvolvimento de produto, mesclam-se as tarefas do desenhista (ou modelista), que executam o desenvolvimento do design, com a montagem das primeiras peças - chamadas "peças-piloto" -, normalmente realizadas dentro das principais firmas, internalizando o know-how envolvido no desenvolvimento dos modelos.

As informações da Tabela 4 confirmam as expectativas tanto para o AAC quanto para o AAL, já que mais de $60 \%$ das empresas internalizam o desenvolvimento do produto nesses aglomerados. A diferença fundamental, nesse caso, é que na $\mathrm{AAC}$ a proporção de empresas que não têm atividades de desenvolvimento de produto $(13,6 \%)$, é muito inferior que no aglomerado Leste $(35,4 \%)$. Ou seja, as infor- 
TABELA 4

Execução de Atividades Relacionadas ao Projeto e Desenvolvimento de Produtos nas Empresas do Vestuário do Aglomerado da Área Central e Leste Município de São Paulo - 2001

Em porcentagem

\begin{tabular}{|c|c|c|c|c|c|c|}
\hline \multirow{2}{*}{ Tarefas Selecionadas } & \multicolumn{3}{|c|}{ Execução de Tarefas no Centro } & \multicolumn{3}{|c|}{ Execução de Tarefas no Leste } \\
\hline & Externas & Internas & Inexistentes & Externas & Internas & Inexistentes \\
\hline Desenvolvimento e Gerenciamento de Projetos & 17,8 & 2,8 & 79,4 & 3,2 & 1,7 & 95,1 \\
\hline Desenvolvimento de Produtos & 19,3 & 67,1 & 13,6 & 3,2 & 61,4 & 35,4 \\
\hline
\end{tabular}

Fonte: Fundação Seade. Pesquisa da Atividade Econômica Paulista - Paep 2001. Elaboração dos autores.

mações relativas às tarefas de desenvolvimento de produto reforçam as evidências de que o AAL possui características tecnológicas mais elementares. Assim, a concentração das chamadas "funções inteligentes" é mais apropriada para o aglomerado central, pois contribuem para a construção de vantagens competitivas mais dinâmicas nessa localidade.

\section{TAXINOMIA E DINÂMICA DAS ESTRATÉGIAS PRODUTIVAS}

As vantagens competitivas do setor do vestuário foram plasmadas pelo processo de especialização da produção, que se aprofundou nas grandes metrópoles, tornando tais regiões uma colcha de retalhos, onde convivem atividades produtivas diversificadas, complexas e heterogêneas. Uma das dimensões dos processos de heterogeneidade na região metropolitana está fundamentada na fragmentação da produção do vestuário, distribuída entre as empresas subcontratadas.

Esse fenômeno, comum nas grandes metrópoles, tanto tenderia a facilitar o ajustamento da produção em virtude das flutuações de mercado e da escala dos novos produtos, como poderia proporcionar às empresas melhores condições competitivas, por meio do direcionamento de seus esforços tecnológicos para tarefas mais condizentes à sua participação econômica em estratégias centradas em custo. Proporcionaria até mesmo externalidades dinâmicas (em casos mais raros produzindo efeitos de eficiência coletiva) e também favoreceria processos de inovação e aprendizado mais efetivos.

Em trabalho de campo encetado pela autora, foi possível identificar a dinâmica da organização da produção, assim como a qualidade dos expedientes da subcontratação - onde a diferença fundamental verificada está na execução das tarefas de produção. Simplificando, optou-se por denominar "produtoras de moda" as firmas que externalizam totalmente as tarefas do processo produtivo - ou seja, as empresas que subcontratam tarefas produtivas. Afinal, como afirmam os produtores entrevistados, praticamente todas as empresas da moda (aquelas que têm relação com o mercado) contratam oficinas para realizar as etapas de produção, principalmente a tarefa "costura".

Assim, as "empresas faccionistas", especializadas em uma única tarefa da produção - como as oficinas de costura, em sua maioria - são normalmente subcontratadas pelas produtoras de moda. Porém, identificou-se uma profunda heterogeneidade quanto à estrutura, organização e porte entre as empresas pertencentes ao segmento "faccionistas" (Quadro 2).

Algumas empresas contratantes, normalmente inseridas em mercados mais competitivos, exigem oficinas que sejam formalmente estabelecidas, com CNPJ e local específico para a produção. Outro ponto crítico verificado diz respeito à capacidade instalada para o atendimento da escala de produção e aos critérios de qualidade, pois, já na fase de contratação, exige-se que determinada oficina tenha um nível mínimo de máquinas e operadores qualificados. Um dos fenômenos mais observados tem sido a subcontratação das tarefas de costura, que se estende a atividades que são realizadas no próprio domicílio do trabalhador (fenômeno conhecido como putting out). Verificou-se ainda a existência de um pequeno subconjunto de firmas que externalizam todas as tarefas da produção, elas operam como intermediárias entre distribuidores e confeccionistas, e por vezes entre confeccionistas e facções. Geralmente, essas firmas negociam preço, tempo de entrega e, em alguns casos, até coordenam a produção.

Há ainda algumas empresas que são caracterizadas por processos de produção tradicional sem uma estratégia produtiva formalmente definida, ora produzindo facção, ora peças encomendadas ou ainda peças de baixo valor agregado. ${ }^{22}$ Obviamente, essa complexa gama de estratégias produtivas tem reflexos significativos na dinâmica de funcionamento dos aglomerados, além de implicações explíci- 
QUADRO 2

Características da Organização Produtiva da Indústria do Vestuário nas Aglomerações da Área Central e Leste Município de São Paulo - 2001

\begin{tabular}{|c|c|c|}
\hline Tipo de Empresa & Tarefas Produtivas Realizadas na Empresa & Tarefas Produtivas Subcontratadas \\
\hline Produtora de Moda & $\begin{array}{l}\text { Tarefas Inteligentes: } \\
\text { - Desenvolve Projeto } \\
\text { - Desenvolve Produto } \\
\text { - Design } \\
\text { - Corta } \\
\text { - Monta Peça Piloto } \\
\text { - Seleciona as Peças } \\
\text { - Etiqueta e Embala }\end{array}$ & $\begin{array}{l}\text { - Subcontratação parcial, essencialmente, as } \\
\text { tarefas mais rotineiras associadas à costura } \\
\text { - Em alguns casos subcontrata atividades } \\
\text { relacionadas ao desenvolvimento de } \\
\text { coleções }\end{array}$ \\
\hline Faccionista & $\begin{array}{l}\text { Tarefas Rotineiras: } \\
\text { - Costura, ou } \\
\text { - Borda, ou } \\
\text { - Lava, ou } \\
\text { - Arremata, etc. }\end{array}$ & $\begin{array}{l}\text { - Na verdade, essas empresas são as } \\
\text { subcontratadas } \\
\text { - Em alguns casos subcontrata tarefas de } \\
\text { costura realizadas em domicilio (putting out) }\end{array}$ \\
\hline Intermediária & $\begin{array}{l}\text { Tarefas de Controle: } \\
\text { - Intermediação entre produtores } \\
\text { e distribuidores }\end{array}$ & $\begin{array}{l}\text { - Subcontrata as tarefas de desenvolvimento } \\
\text { e design } \\
\text { - Subcontrata tarefas associadas à costura }\end{array}$ \\
\hline Vestuário Não-Especializado & $\begin{array}{l}\text { Tarefas Não-Especializadas } \\
\text { - Desenha } \\
\text { - Corta } \\
\text { - Monta Peça Piloto } \\
\text { - Etiqueta e Embala } \\
\text { - Realiza facção } \\
\text { Tarefas Rotineiras } \\
\text { Tarefas de Controle }\end{array}$ & $\begin{array}{l}\text { - Altamente verticalizada } \\
\text { - Realiza as tarefas de produção internamente } \\
\text { - Por vezes é subcontratada para realizar } \\
\text { tarefas de produção }\end{array}$ \\
\hline
\end{tabular}

Fonte: Fundação Seade. Pesquisa da Atividade Econômica Paulista - Paep 2001. Elaboração dos autores.

tas para a qualidade das interações interfirmas, como a introdução de inovações e o fortalecimento de competências, além da já citada precariedade das relações de produção. As informações captadas pela Paep 2001 sobre a intensidade das estratégias de subcontratação de tarefas demonstram que tais expedientes são mais praticados no AAC (40\%) do que no AAL (28\%), sugerindo também que as empresas do AAL apresentam configurações produtivas mais verticalizadas (44\%) do que aquelas presenciadas no AAC (21\%) (Tabela 5).

Com base nos trabalhos de campo observou-se que, no aglomerado da AAC, grande parte das empresas é produtora de moda, ou seja, são firmas que tendem a se especializar nas funções inteligentes, com elevados padrões de subcontratação de tarefas produtivas e serviços. As firmas "faccionistas" apresentam uma participação relativa importante nessa localidade; e o segmento de empre- sas intermediárias - aquelas que se dedicam unicamente à coordenação da produção e comercialização de peças produzidas integralmente por outras indústrias - representa uma pequena fração desse aglomerado. As empresas que não têm participação econômica definida, denominadas de "vestuário não-especializado" - aquelas que se dedicam ora à facção e ora à produção de peças para mercados que concorrem essencialmente pelo preço - representam também uma parcela modesta desse aglomerado. Segundo informações da Paep 2001, 66\% das vendas do AAC destinam-se a empresas pertencentes à cadeia produtiva têxtil-vestuário (Tabela 5). Assim, podese afirmar que o aglomerado da AAC tem uma estratégia produtiva essencialmente especializada e dinâmica, pois as firmas centram esforços em funções específicas e especializadas, inclusive no segmento de empresas de facção. 
TABELA 5

Informações de Subcontratação das Tarefas de Produção e Destino das Vendas dos Aglomerados da Área Central e Leste Município de São Paulo - 2001

\begin{tabular}{lcc} 
& & Em porcentagem \\
\hline Padrões de Externalização da & Central & Leste \\
Produção e Destino das Vendas & & \\
\hline Externalizam Parcialmente & 40,1 & 28,3 \\
Externalizam Integralmente & 4,0 & 7,1 \\
Não Externalizam & 21,0 & 44,5 \\
Vendem a Maior Parte da Produção & & \\
para a Cadeia Têxtil-Vestuário & 55,9 & 64,6 \\
\hline
\end{tabular}

Fonte: Fundação Seade. Pesquisa da Atividade Econômica Paulista - Paep 2001. Elaboração dos autores.

No AAL, as empresas produtoras de moda têm participação mais modesta na dinâmica de funcionamento. As faccionistas "puras" representam uma parcela relativamente pequena, o que não deixa de ser surpreendente. Porém, esse dado for associado ao fato de que o produto do AAL é reconhecidamente mais simples e de menor preço, além de oferecer baixíssimas barreiras à entrada no mercado, é possível sugerir que uma parcela das oficinas faccionistas oferece parte de sua produção diretamente ao mercado. Outro dado importante levantado pela Paep 2001 indica que $66 \%$ das empresas desse aglomerado vendem a maior parte da produção para a cadeia do vestuário - o que parece denotar sua participação econômica no fornecimento de produtos para essa cadeia produtiva. Tal hipótese é corroborada pelo fato de que as firmas do vestuário tradicional formam o maior conjunto desse aglomerado, com proporção superior à verificada no AAC.

Ressalta-se que a estratégia produtiva de baixa participação econômica utilizada pelas empresas do segmento tradicional do AAL contraria a lógica da participação econômica flexível (SCOTT, 1994), aparentemente também não revelando padrões superiores de competitividade e trajetórias sustentáveis de aprendizado e de esforço tecnológico, influenciando negativamente a dinâmica dessas empresas. Assim, a participação econômica produtiva no AAL ocorre de forma precária - o que provavelmente tem implicações diretas negativas sobre a performance da produtividade e competitividade desse aglomerado. Comparando as empresas do AAC e do AAL, fica claro que o primeiro tem um conjunto mais equilibrado, mais especializado e dinâmico, delineando elementos potenciais de funcionamento mais próximos da estratégia de participação econômica flexível. Já o segundo caminha mais lentamente nessa mesma direção, mas mantém certo atraso, fato que provavelmente seja decorrente das já citadas características produtivas e empresariais desse aglomerado, que tendem a proporcionar maior precariedade na interação com o mercado, assim como na relação interfirma.

\section{MECANISMOS INSTITUCIONAIS (FORMAIS E INFORMAIS) DE INTERAÇÃO ENTRE OS ATORES}

Nas visitas e entrevistas aos aglomerados produtores do vestuário do AAC e do AAL, buscou-se levantar a existência de atividades complementares à cadeia de produção que conferem sustentação ao aprendizado, troca de informações e interação entre os atores. No caso de aglomerações metropolitanas, é possível dizer que as instituições que dão apoio às atividades dos aglomerados operam de forma local e "global". Verifica-se que nos últimos 10 anos houve um movimento de valorização de eventos ligados à nova indústria da moda de forma ampla: como o agendamento e organização da versão paulista da maior feira internacional de moda (São Paulo Fashion Week); o fortalecimento da Feira Nacional da Indústria Têxtil - Fenit; Encontros da Moda; Instituto da Moda, além de vários outros eventos ligados à promoção de coleções, exposição da produção e lançamento de novos profissionais de design. Há também algumas iniciativas que se destinam a atender os interesses do setor, como as realizadas pelo Centro de Estudos, Tecnologia e Informações de Moda Caio Alcântara Machado - Cetim (ligado à Associação Brasileira do Vestuário - Abravest), e as assessorias da Associação Brasileira da Indústria Têxtil e Vestuário - Abit. Por estarem relativamente próximos a essas instituições, os aglomerados estudados tendem a absorver melhor esses esforços, mas é importante destacar que existem iniciativas que atendem as aglomerações de forma mais direcionada.

No AAC foram identificadas algumas organizações que dão apoio e qualificação. Dentre elas, destaca-se a Câmara dos Dirigentes do Bom Retiro, que representa os interesses políticos e econômicos de um grupo de empresários locais. Por meio dela, eles buscam parcerias para reciclagem tecnológica - principalmente junto à escola "Adriano José Marchini" - do Senai - que foi uma das primeiras escolas a disponibilizar cursos voltados para a indústria do vestuário e está instalada no próprio distrito do Bom Retiro. Outra instituição localizada no aglomerado Central é o consórcio Tropical Spice, que foi criado para absorver a produção das empresas consorciadas e exportá-la com sua própria marca. Destaca-se também 
Associação Brasileira da Indústria e Comércio de Máquinas para Costura - a Abramaco, além de escolas e cursos de moda de nível básico.

Não foi encontrado nenhum consórcio ou associação que faça compras de insumos ou uso de máquinas em conjunto, mas foram identificados cafés e livrarias que acabaram se transformando em pontos de troca de informações formais e informais, possibilitando o acesso a publicações, revistas e livros, assim como contatos pessoais entre empresários e designers que freqüentam esses locais. A essas instituições somam-se várias escolas de educação profissional de nível básico e o Núcleo de Ação Empresarial do Projeto Bom Retiro - uma organização não-governamental da qual fazem parte alguns estilistas, empresários, comerciantes e urbanistas - cujo projeto prevê a criação de uma Escola de Moda e a revitalização física do distrito. No AAL foi identificado o "Alô Brás", que é a câmara dos dirigentes locais que reúne alguns grandes pontos de comercialização de produtos e disponibiliza boa estrutura para os compradores, pois funciona como um shopping atacadista onde também ocorrem eventos, cursos e até mesmo desfiles. A Área Leste também conta com algumas escolas de educação profissional de nível básico. Não foi possível identificar consórcios, associações ou representações de classe que organizem os interesses e promovam o desenvolvimento local.

Destaque-se que as organizações que oferecem algum tipo de apoio ao AAC parecem estar mais voltadas para as novas demandas das empresas do que as ligadas ao AAL. Porém, ainda há um longo percurso institucional a ser percorrido. Na verdade, os dois aglomerados, assim como o próprio setor do vestuário, enfrentam alguns problemas decorrentes da formação de grupos com interesses distintos - o que é, em parte, decorrente da própria segmentação do setor, fato que dificulta a elaboração de ações concertadas por parte dos atores em direção ao desenvolvimento econômico e à construção de mecanismo coletivos de aprendizado e inovação tecnológica.

\section{CONCLUSÃO}

Como demonstramos ao longo deste artigo, a concorrência na indústria do vestuário vem sendo cada vez mais determinada pelos critérios de diferenciação (preço-qualidade-criatividade). Ou seja, ela está mais centrada em estratégias de desenvolvimento de produtos que possam incorporar os conceitos de estilo e design, moda, estratégias de marketing e valorização de marca - os mesmos conceitos que acabaram por edificar novas barreiras à entrada para os países, regiões ou SPILs que competem por esse mercado. Para a indústria do vestuário do Município de São Paulo, pode-se afirmar que embora tenha sido presenciado um processo de desconcentração produtiva, a metrópole continua sendo expressivamente relevante para a dinâmica do setor no Estado de São Paulo e no Brasil.

Observa-se ainda um crescimento dos padrões de assimetria tecnológica e heterogeneidade produtiva, que variam desde a utilização de novas competências (como as chamadas funções inteligentes - embora estas sejam muito concentradas em pequenos grupos) até a reprodução, em larga escala, de estratégias de "competitividade espúria”. Nesse sentido, essas estratégias agressivas de flexibilização e redução dos custos de trabalho - especialmente por meio da intensificação do uso de vínculos precários e inseguros de trabalho, tais como a utilização do trabalho a domicílio e de imigrantes ilegais - não diferem do que já foi verificado nas experiências internacionais mais bem-sucedidas. ${ }^{23}$

No tocante ao foco deste estudo, ressalta-se a identificação de pelo menos dois grandes aglomerados produtivos relevantes no Município de São Paulo: o Aglomerado da Área Central e o Aglomerado da Área Leste. Também foi possível observar, através de análise comparativa, que os padrões competitivos são bastante distintos - o que reforça o caráter heterogêneo das atividades produtivas da Região Metropolitana de São Paulo. O AAC apresentou melhores condições de apropriar-se das capacidades inovadoras disponibilizadas pela metrópole relacionadas com os ativos da moda e com os efeitos multiplicadores dos agentes envolvidos na cadeia de produção - ainda que o produto final desse aglomerado não seja característico da alta costura, mas sim de prêt-à-porter, proporcionando condições suficientes para que esse aglomerado se fortaleça em função de uma identidade própria.

Já para o caso do AAL, as condições de constituição foram mais limitadas, pois conduziam a trajetórias de aprendizados mais restritas, como conseqüência de sua participação econômica competitiva voltada para produtos de menor preço - o que requer menor esforço tecnológico e pouco investimento em design. Ou seja, as estratégias tecno-produtivas da maior parte das empresas desse aglomerado estão inseridas em um segmento em que a competitividade fundamental baseia-se na escala e no preço. No entanto, isso não significa que é uma estratégia frágil, mas sim que está direcionada aos segmentos mais reprodutores - o que possibilitaria sua inserção nas cadeias 
produtivas internacionais. Em grandes linhas, concluímos que o mercado existente na metrópole permite tanto a existência e a manutenção de atividades industriais e de serviços mais tradicionais no setor do vestuário, assim como as atividades mais sofisticadas encontradas nas grandes metrópoles mundiais, como Nova York, Londres, Paris e Milão, dentre outras.

O último ponto remete-se a responder a pergunta inicial deste artigo: simples aglomerados ou sistema produtivos inovadores? Sendo assim, o AAC, ainda que desarticulado, apresentou mais elementos que o potencializam como uma "trajetória evolutiva e embrionária" (na acepção neo-schumpeteriana) de um sistema produtivo local inovador. O AAL, ainda que tenha apresentado características para ser considerado um sistema produtivo, possui interação e aprendizado tecnológico de vínculos mais fracos - ou seja, é ainda um aglomerado de interações "incipientes", dando elementos suficientes para considerar a estrutura do vestuário da metrópole como uma colcha de retalhos de aglomerações que se distinguem e se complementam ao mesmo tempo. Com efeito, considerando as vocações produtivas e competitivas desses aglomerados, observa-se que a consolidação, amadurecimento e transição para padrões superiores de funcionamento dependerá de um esforço conjunto entre os atores da esfera público e privada. Entretanto, o desenvolvimento e o fomento à inovação (sobretudo na formação de lideranças na concepção "da moda ou do produto brasileiro”, uma vez que há espaço no mercado nacional e internacional para este tipo de empreendimento), dependerá da implementação de políticas específicas.

Uma política de inovação para o setor da moda deve ter como foco: a valorização e fortalecimento de trajetórias de internacionalização de marcas (apoio à exportação); apoio às estratégias de marketing de inteligência (conhecimento e acesso aos novos mercados); e estímulos à inovação em design nacional, como elementos críticos de agregação de valor e competitividade para esse segmento. Afinal, deve-se considerar que existem espaços tanto no mercado nacional como no plano internacional para esse tipo de empreendimento. Ademais, o delineamento das políticas públicas deverá centrar-se no apoio e incentivo aos fatores dinamizadores da competitividade dos produtores, visando a adensar as relações entre as empresas e instituições de ensino e prestação de serviço. Além disso, os policy markers podem realizar ações no sentido de reduzir a informalidade dessa indústria, através de mecanismos de microcrédito e fomento ao crescimento e profissionalização dos negócios, ou explorar a utilização de um "selo de responsabilidade social".

\section{NOTAS}

Os autores agradecem as leituras críticas e as recomendações elaboradas por Vagner Bessa, Carlos Roberto França e André Nagy, advertindo, como é de praxe, que qualquer erro que por ventura conste deste trabalho é de inteira e exclusiva responsabilidade dos autores.

1. Entre os projetos analíticos que se inscrevem nessa abordagem podemos citar a rede de estudos coordenada por Cassiolato e Lastres (2001), os estudos sobre empresas de base tecnológica - EBTs, de Pinho, Côrtes e Fernandes (2001) e, mais recentemente, os trabalhos sobre SPILs no Estado de São Paulo realizados por Suzigan, Furtado, Garcia e Sampaio (2005). Recentemente, Suzigan et al. (2005) identificaram sete sistemas produtivos na RMSP, que operam como Vetores Avançados.

2. A Redesist (Rede de Pesquisa em SPILs) define sistemas produtivos e inovativos locais (SPILs) como conjuntos econômicos políticos e sociais localizados em um mesmo território, que desenvolvem atividades econômicas correlatas e apresentam vínculos expressivos de produção, interação, cooperação e aprendizagem. Essas configurações incluem produtoras de bens e serviços finais, fornecedoras de equipamentos e outros insumos, prestadoras de serviços, comercializadoras, clientes, cooperativas, associações e demais organizações voltadas à formação e treinamento de recursos humanos, informação, $\mathrm{P} \& \mathrm{D}$ e engenharia, promoção e financiamento. Já os arranjos produtivos locais (APLs) são aqueles casos fragmentados e que não apresentam significativa articulação entre os agentes (GLOSSÁRIO DE APLs, 2005).

3. Em estudo realizado sobre o complexo têxtil, de vestuário e de calçados na Região Metropolitana de São Paulo, Garcia e Cruz Moreira (2004) utilizaram complementarmente dados de três bases de informações disponíveis no Brasil e no Estado de São Paulo. Primeiro, a base da Relação Anual de Informações Sociais - Rais, do Ministério do Trabalho e do Emprego - MTE, que apresenta dados de emprego e estabelecimentos (entre outros), e tem sido amplamente utilizada em trabalhos que analisam sistemas locais de produção. Segundo, a base de dados da Pesquisa Industrial Anual PIA, do Instituto Brasileiro de Geografia e Estatística - IBGE, que apresenta as informações de número de estabelecimentos, receita líquida de vendas, pessoal ocupado e valor da transformação industrial. E terceiro, a Paep, cuja primeira tomada foi realizada em 1996, sendo a segunda abordagem de campo realizada em 2001. É interessante notar que os resultados e conclusões obtidos por esses autores expressam as mesmas tendências e impressões apontadas pela Paep 2001, ou seja, a existência de uma forte concentração da indústria do vestuário na cidade de São Paulo e o significativo volume de pessoal ocupado no setor.

4. Para obtenção de outras informações sobre a metodologia da Paep, ver: <http://www.seade.gov.br/produtos/paep/index.html>.

5. As estimativas utilizadas neste estudo são alternativas ao desenho dos domínios da Paep, por isso foi necessário calcular o coeficiente de variação e analisar o intervalo de confiança. Além disso, as estimativas que identificaram os aglomerados foram ainda comparados com os dados do Cadastro Cempre (IBGE).

6. Codificação de endereçamento postal (CEP) por região de São Paulo (GUIA-MAPOGRAF, 1996, p. 790-791).

7. O QL indica a concentração relativa de uma determinada indústria numa região comparativamente à participação da mesma com a de outras, em um determinado espaço - o qual, neste estudo, foi definido como o Estado de São Paulo. Assim, a verificação do QL superior a um (1) indica alta concentração da estrutura de produção local numa dada atividade.

8. Embora seja possível encontrar no AAC algumas indústrias voltadas para a alta costura, principalmente no segmento de moda praia, como a Rosa Chá. 
9. O termo capital social refere-se a um conjunto de instituições formais e informais que incluem hábitos e normas sociais que afetam os níveis de confiança, interação e aprendizado em um sistema social. O reconhecimento da importância desse termo referese à consideração crítica da estrutura e formação das relações sociais para compreender e intervir na dinâmica econômica de um determinado espaço e território. Assim, elevados níveis de capital social propiciam relações de cooperação que favorecem o aprendizado interativo, como acontece com a transmissão do conhecimento tácito. Esse termo foi elaborado a partir dos trabalhos pioneiros dos sociólogos Pierre Bourdieu, James Coleman e Robert Putnam (GLOSSÁRIO DE APLs, 2005).

10. A aparente falta de segredos da produção de vestuário fez com que o interesse pela formação de profissionais especializados para esse mercado tenha sido tardia, atraindo empreendedores que trabalhavam em outros setores, o que acabou por determinar a forma precária com que muitas dessas unidades produtivas fossem organizadas e ativadas. Esse fato é corroborado pela própria política educacional de formação de profissionais para esse mercado, pois é recente o interesse das instituições de ensino superior em formar um profissional de negócio voltado para a nova indústria do vestuário, ou seja, a moda.

11. Algumas regiões apresentam elevada concentração de produtores com atividade na indústria têxtil e de vestuário. São exemplos: a região de Americana, na produção de tecidos planos artificiais e sintéticos; a cidade de Ibitinga, na de bordados; a região do Circuito das Águas, na confecção de malhas, entre outras. Ver, SOUZA e GARCIA (1999).

12. O município de Amparo abriga um aglomerado de indústrias de confecção infantil formado por empresas de pequeno e médio porte. Ver, NAKAMATSU E FURTADO (2003).

13. Os parâmetros da moda têm sido ditados pelas maisons dos principais centros internacionais e difundidos pela mídia, direcionando a dinâmica do mercado. Os principais centros geradores de moda são Paris, Milão, Londres e Nova York, ressalva feita para o segmento de surf wear, cujos centros de referência são o Havaí e a Austrália. A cada estação são lançadas novas coleções com mudança nos tecidos, padronagens, cores e modelos, o que afeta toda a cadeia produtiva têxtil e de vestuário. Quanto menor for o ciclo de desenvolvimento de novos produtos, maior a necessidade de intensificação das relações na cadeia produtiva têxtil/vestuário, no sentido de flexibilizar o setor para melhor atender as demandas do consumidor final.

14. A referência conceitual e metodológica da Pesquisa de Inovação Tecnológica na Paep teve como base o Oslo Manual: proposed guidelines for collections and interpreting technological innovation data (1997). A pesquisa de inovação foi harmonizada com a experiência do modelo recomendado pela Eurostat, consagrado na terceira versão da Community Innovation Survey (CIS-III). A principal crítica ao conceito de inovação tecnológica adotado pelo Manual de Oslo, considerando-se o setor de vestuário, é ao critério de exclusão dos esforços de design, como já ressaltara Kontic (2001).

15. É importante frisar que é esperado que as aquisições de máquinas e equipamentos tenham uma participação importante no esforço tecnológico no setor de vestuário, pois essa atividade é pautada pelo binômio máquina/operador. Conseqüentemente, estes dois elementos têm um peso expressivo na dinâmica econômica e tecnológica do setor. Nesse caso, o diferencial são os esforços direcionados aos ativos intangíveis.

16. Foram computados pela Paep, os investimentos em patentes, contrato de fornecimento de tecnologia e o direito de uso de marcas. Embora formem a base dos indicadores mais utilizados para analisar o esforço tecnológico, essas informações mostram-se limitadas para os setores muito dependentes de design, como já foi discutido anteriormente.

17. Nesse item, a Paep computou os investimentos com equipamentos de informática, móveis, etc.
18. Assim as empresas que possuem capacidade inovativa ou ativos comerciais estabelecidos (canais de comercialização ou marcas próprias), suportados por mecanismos de financiamento, são capazes de comandar sua cadeia de produção, determinando os parâmetros de funcionamento dos atores nela inseridos (LUPATINI, 2004; GARCIA; CRUZ-MOREIRA, 2004).

19. Ciclo do desenvolvimento do design: o desenvolvimento das coleções é um trabalho que possui uma dinâmica bastante específica. $\mathrm{O}$ ciclo de atividades inicia-se com a ida dos estilistas e especialistas em moda para os centros geradores de informações e conceitos. Essa fase de pesquisa de tendências inclui os desfiles dos principais estilistas internacionais, as principais revistas de moda e as "tendências de rua" dos centros geradores. Com base nessa bagagem e o tema estabelecido para a nova coleção, os estilistas começam a desenhar os modelos, a escolher os tecidos e padronagens e a subsidiar as atividades de marketing e promoção. Ao término desta, parte-se para a confecção da peça-piloto, que depois é repassada para as empresas produtoras, em sistema de facção.

20. As atividades de marketing e promoção envolvem o trabalho de criação e consolidação da marca, bem como da estratégia de comunicação do conceito, por meio da mídia. Preocupam-se também com o estabelecimento de canais de comunicação com o cliente, que englobam centrais telefônicas (0800), home pages na Internet e convites para participação em eventos promocionais. É nessa área que são elaboradas as estratégias de lançamento das coleções. O projeto do ponto de venda envolve a definição da arquitetura, decoração, iluminação e vitrine. As empresas dispõem de arquitetos e decoradores que traduzem para o ponto de venda o conceito trabalhado pela marca e pelos estilistas, ou, eventualmente, trabalham com consultores.

21. Ciclo do desenvolvimento de fornecedores: o desenvolvimento de fornecedores é uma atividade crítica nesse tipo de estratégia, uma vez que grande parcela da produção é terceirizada. As empresas envolvidas nessa atividade fazem o detalhamento do projeto para a produção e determinação das especificações do produto, e também estabelecem os critérios para o controle de qualidade. Essa área também contribui com pesquisas de novos materiais, corantes, tecidos, padronagens e embalagens feitas em parceria com os fornecedores, que auxiliam os estilistas no desenvolvimento das coleções. Normalmente, os principais requisitos são: a flexibilidade do sistema de produção, pois há demanda de produção em pequenos lotes e grande variedade de produtos, bem com prazos de entrega reduzidos; e a garantia da qualidade do produto, que consiste na exigência de permanência no cadastro de fornecedores.

22. Essas formas de produção têm aprofundado a precarização nas relações de trabalho na indústria do vestuário, fenômeno já antigo no setor, verificado até mesmo nos aglomerados ancorados em relações socioeconômicas mais fortes, como os localizados na Terceira Itália. Em estudo recente sobre o setor, Leite (2004, p. 1) alerta que no vestuário "se multiplicam novas e velhas formas de trabalho, como o trabalho temporário, a domicílio, part time, etc., que, em vez de marginais ao desenvolvimento econômico, se mostram altamente funcionais".

23. Para um relato das experiências internacionais de reestruturação e inserção no comércio global, ver o estudo de Garcia e Cruz-Moreira (2004).

\section{REFERÊNCIAS BIBLIOGRÁFICAS}

ARAÚJO, M. de F.I. Impactos da reestruturação produtiva sobre a Região Metropolitana de São Paulo no final do século $X X$. Tese (Doutorado) - Instituto de Economia, Unicamp, Campinas, 2001.

BENKO, G. Economia, Espaço e Globalização. São Paulo: Hucitec, 2002. (1. ed. 1995). 
BESSA, V. O setor de serviços às empresas. In: EMURB/ CEBRAP. (Org.). Caminhos para o centro. São Paulo 2004

CANO, W. A interiorização do desenvolvimento econômico do Estado de São Paulo. São Paulo: Fundação Seade/Unicamp, 1988

CASSIOLATO, J.E.; LASTRES, H.M.M. O foco em arranjos produtivos e inovativos locais de micro e pequenas empresas. In: LASTRES, H.M.M; CASSIOLATO, J.E; MACIEL, M.L. (Org.). Pequena empresa: cooperação e desenvolvimento local. Rio de Janeiro: Relume Dumará, 2003.

COMIN, A. et al. Estratégias de desenvolvimento econômico para a Área central do Município de São Paulo. São Paulo, Cebrap/CEM. Relatório de pesquisa, 2002.

FUNDAÇÃO SEADE. Pesquisa da Atividade Econômica Paulista: uma metodologia de produção de dados e conhecimento. São Paulo em Perspectiva. São Paulo, Fundação Seade, v. 13, n. 1-2, p. 23-39, jan./jun. 1999.

FURTADO, J. Limites e possibilidades do Brasil nas configurações produtivas globalizadas uma análise apoiada em diversas cadeias. III Relatório Parcial de Pesquisa. Geein/DE/Unesp e Ipea, 2000.

GARCIA, R. e CRUZ-MOREIRA, J. R. O complexo têxtilvestuário: um cluster resistente. Brasil. In: EMURB/CEBRAP (Org.). Caminhos para o centro. São Paulo: 2004.

GLOSSÁRIO DE APLs, 5. revisão, jun. 2005. Disponível em: <http://www.ie.ufrj.br/redesist>. Acesso em 18 ago. 2005.

GUIA-MAPOGRAF. 26 ed. São Paulo: 1996.

HADDAD, P.R. Medidas de localização e de especialização. In HADDAD, P.R. et al. (Org.). Economia Regional: Teorias e métodos de análise. Fortaleza: BNB-ETENE, 1989.

KONTIC, B. Redes produtivas e aprendizado na indústria do vestuário da RMSP. In: ENCONTRO DA ASSOCIAÇÃO BRASILEIRA DE ECONOMIA REGIONAL, 2., Anais... São Paulo, FEA/USP, 2002.

Aprendizado e metrópole: a reestruturação produtiva na indústria do vestuário em São Paulo. Dissertação (Mestrado) - FFLCH/USP, São Paulo, 2001.

LEITE, M. de P. Tecendo a precarização: gênero, trabalho e emprego na indústria de confecção em São Paulo. In: ENCONTRO ANUAL ANPOCS, 28., Anais... Caxambu, 2004.

LUPATINI, M. Relatório setorial preliminar - Têxtil e vestuário. Finep - Rede DPP, 2004. Disponível em:

<http://www.finep.gov.br/portaldpp/index.asp\#>.

MATTEO, M.; TAPIA, J.R.B. Características da indústria paulista nos anos 90: em direção a uma city region? Revista Sociologia Política, Curitiba, n. 18, p. 73-93, jun. 2002.

NADVI, K.; SCHMITZ, H. Industrial clusters in LDCs: review of experiences and research agenda. IDS Discussion Paper, n. 339. Brighton, University of Sussex, 1994.

NAKAMATSU, R.Y.Y; FURTADO, A.T. Aglomerações em cidades médias paulistas: o segmento de confecção infantil em Amparo. PMA/DPCT. 2003. Relatório final.
NEGRI, B. Concentração e desconcentração da indústria em São Paulo (1880-1990). Tese (Doutorado) - Instituto de Economia/Unicamp, Campinas, 1994.

PACHECO, C.A. A fragmentação da nação. Tese (Doutorado) - Instituto de Economia/Unicamp, Campinas, 1998.

PINHO, M., CÔRTES, M.R. E FERNANDES, C.A. A fragilidade das empresas de base tecnológica em economias periféricas: uma interpretação baseada na experiência brasileira. Finep Rede DPP, 2001. (Textos para discussão). Disponível em: <http://www.finep.gov.br/portaldpp/textos/uploads/ Art_EBT_Micro.pdf>.

SCOTT, A. La economia metropolitana. In: BENKO, G.; LIPIETZ, A. Las Regiones que Ganan. València: Alfons el Magnànim, 1994. p. 103-119.

SOUZA, M.C.; GARCIA, R. Sistemas locais de inovação em São Paulo. In: CASSILATO, J.E.; LASTRES, H.M.M. (Ed.) Globalização e inovação localizada. Brasília: MCT-CNPq, 1999.

STORPER, M. The Regional World. New York: The Guilford, 1997.

STORPER, M.; SALAIS, R. Worlds of Production.

Massachusetts: Harvard, 1997.

STURGEON, T. Does manufacturing still matter? The organizational delinking of production from innovation. Berkeley, CA: Berkeley Roundtable on the International Economy, 1997. (BRIE working paper; 92B).

SUZIGAN, W.; FURTADO, J.; GARCIA, R. Clusters ou sistemas locais e inovação: identificação, caracterização e medidas de apoio. São Paulo: Iedi, 2002.

SUZIGAN, W.; FURTADO, J.; GARCIA, R.; SAMPAIO, S. A dimensão regional das atividades de C\&T\&I no Estado de São Paulo. In: FAPESP. Indicadores de C\&T\&I São Paulo 2004. São Paulo: 2005.

Aglomerações industriais no Estado de São Paulo. Economia Aplicada, v. 5, n. 4, p. 695-717, out./dez. 2001.

TINOCO, A. de C. Competitividade, inovação e localização: repensando o conceito de centralidade da Região Metropolitana de São Paulo para a dinâmica regional brasileira. Dissertação (Mestrado) - Cedeplar/UFMG, 2001.

Maria das Graças Brito: Mestre em Política Científica e Tecnológica pelo IGE/Unicamp (gracabrito@ige.unicamp.br).

Roberto Bernardes: Doutor em Sociologia pela USP, Professor Adjunto da Escola Superior de Propaganda e Marketing e Analista da Fundação Seade (rcbernar@seade.gov.br).

Artigo recebido em 7 de maio de 2005 Aprovado em 10 de junho de 2005. 